\title{
DPX-E7 HPV Vaccine
}

National Cancer Institute

\section{Source}

National Cancer Institute. DPX-E7 HPV Vaccine. NCI Thesaurus. Code C131494.

A therapeutic vaccine composed of a synthetic peptide consisting of amino acids 11

through 19 of the viral oncoprotein human papillomavirus (HPV) subtype 16 E7 (HPV16-

E7 11-19), with potential antineoplastic and immunostimulating activities. Immunization with the DPX-E7 HPV vaccine may stimulate the host immune system to mount a cytotoxic T-lymphocyte (CTL) response against tumor cells expressing the HPV16-E7 protein. HPV type 16 plays a key role in the carcinogenesis of certain cancers. 